\title{
Ceramic Product Design based on Digital Art
}

\author{
Zhang Sancong \\ Jingdezhen University of ceramics 333403
}

Keywords: traditional ceramic product design, hand-made digital art creation practice

\begin{abstract}
Ceramic product design is an ancient and young subject. There are many deficiencies in the design of traditional ceramic products mainly made by hand. Digital art is an art form with the aid of or part of computer technology in the process of creation. It can make up for the defects in the traditional ceramic product design with its unique advantages, and bring new vitality and vitality for the design of ceramic products. Starting from the design of ceramic products, this paper introduces the process of traditional ceramic design and analyzes its shortcomings. Then, by introducing digital art, analyzing the advantages brought by digital art, the benefits of digital art to ceramic product design is discussed.
\end{abstract}

\section{Traditional ceramic product design}

\subsection{Process of traditional ceramic product design}

(1) Draw the sketch, the effect map - the designer records the design inspiration in the form of sketching, and selects the feasible design scheme to improve it. Then, the finalized sketch plan is made in detail and concretely with the Mark pen, the color lead, the water powder or the brush. Show communication.

(2) Draw the design drawings - according to the draft and the effect drawing after the finalization, calculate the size and volume of the product, and draw the design drawings with the tools of the needle tube pen, drawing pen and the ruler, the triangle plate, the curve plate, the compass and so on.

(3) Making the entity model - mixing the gypsum powder and water in a certain proportion and pouring out the basic molding of the ceramic products. According to the design drawings, the model of the product is made by turning the model locomotive or cutting by hand. Plane drawings and stereoscopic products are very different in body size, so that we can better grasp the shape, volume and proportion of products.

(4) Improvement of the scheme - through the entity model, the designer will find some deficiencies in the design, so that the model and the drawings will be modified to improve the design.

(5) Decorative design of flower paper -- decorative pattern on the ceramic body. When designing flower paper, we need to measure the size of the flower paper on the three-dimensional model, and expand the plane drawing according to the radian of the model, and then draw the decorative pattern. Finally, we use ceramic pigments to match colors and make screen prints.

(6) Making moulds, grouting and making billets -- making plaster mould with gypsum model. After the mold is dried, the mold is closed, the mud is injected, and the water of the mud is absorbed by a part of the plaster mold, and then a clay ceramic product body can be obtained by the mold.

(7) The ceramic products made of porcelain, which are made of grouting, are made of clay, and they are glazed after full drying and then into the kiln. After the high temperature of more than 1000 degrees, the porcelain products are made.

(8) Decals, roast flowers - the printed ceramic decorative paper, attached to the product's porcelain, and then into the kiln, after 800 degrees of high temperature, the flower paper is baked on 
the porcelain.

\subsection{Problems in the design of traditional ceramic products}

\subsubsection{Manual production is large, accuracy and efficiency are not high}

Manual design accounts for a large proportion in ceramic product design and many tasks need to be done manually by designers. For example, when a plaster model is used, a large shape is usually poured out with a plaster cast, and then chipped with a car model locomotive or by hand. In this process, the designer cannot completely reclose the drawings, the drawings and the models, and the differences between the drawings and the models, and the precision of the product, so that the precision of the product design can be easily made. Drop. As for the drawing of the ceramic product, the designer uses the tools such as brush, Mark pen, brush, color powder and other tools to draw a stereoscopic product effect map on the plane drawing, and use the lines, bright and dark, to shape the modeling body, and use the descriptive geometry to show the Perspective relationship. This stereoscopic effect, with the help of light and shade, is only a visual illusion of the human eye. The accuracy is not high, and sometimes it cannot show the form of the product very well.

\subsubsection{The development cycle is long and the cost is high}

In order to perfect the three-dimensional effect of ceramic products, designers often make plaster models and samples to observe the shape of products. In the traditional design of ceramic products, when we design the ceramic model, the whole design process is often to find out the shape, the use, the sense of quantity and the sense of quality, and finish the final design. Therefore, the design will be modified and adjusted repeatedly. In the process of ceramic design, the gypsum model, plaster mold and the mud billet of the product need to be dry. In the rainy or wet season, if there is no drying equipment, the model, mold, and the blank body are not fully dried, the next work cannot be carried out, and the design work is lagging behind. In this way, it will cost a lot of money and time to complete the ceramic design, which will increase the design cost.

\subsubsection{Unitary means of communication and communication}

In the design process, the communication between designers, designers and customers is very important. In the traditional ceramic product design, before the product is finished, the communication of the design and the communication of the information are mainly through the static effect map and the model. Now, the cross regional and transnational cooperation is becoming more and more frequent. This static effect diagram and model cannot meet the current needs in the communication and communication of the design.

\section{Ceramic product design based on Digital Art}

\subsection{What is digital art?}

Digital art is also known as digital media art, computer art, digital art, and new media art. "Digital media art refers to the artistic form of integrating human rational thinking with the perceptual thinking of art", "digital media art is based on digital technology and modern media technology." "Digital media art" is "digital media art" or "computer beauty". "Digital media art is an artistic form based on digital technology and modern media technology." Li Sida Surgery. His application forms include other visual arts or designs created by digital or digital media. "Digital media art can be defined as the work of digital art itself. It can also be defined as the art of using computer and digital technology to participate in or part of the creation of creation process."

Since the art of full or partial use of computer and digital techniques in the process of creation can be called digital art, and many kinds of art can be completed by computer and digital technology, the concept of digital art is very broad, and it can include painting, sculpture, and music 
completed with digital technology. Pure art, such as dance, can also include product design, environmental design, graphic design, digital film and television, digital design, multimedia design, web design, digital animation, virtual reality and so on with digital technology as the carrier of practical art, so digital art has the dual properties of art and design.

The application of 2.2 digital arts in the design of ceramic products

In the design process of ceramic products, designers have to complete several tasks: design and decoration design, presentation of effect drawings, drawing of design drawings, production of physical models and communication of design. In the traditional ceramic product design process, these tasks are mainly accomplished by hand drawing and handwork. With the popularity of digital technology, the following digital art forms have played an active role in the design of ceramic products.

\subsection{Handlers of drawings and decorations -- graphic digital art}

Plane graphic software, such as Photoshop, CorelDraw, Illustrator, Painter, is created on two-dimensional plane, which can accomplish the tasks of design sketches, two-dimensional effects, paper design and design drawings in the design of ceramic products.

Digital sketches. Sketch is an important way for designers to record inspiration and accumulate materials. They often draw on paper with pencil and Mark pen. In modern design life, digital drawing technology with digital board is becoming more and more mature. Many designers are also used to use digital board and plane design software to record design inspiration and design the sketches of products. Although it is not as convenient as a pencil and sketchbook, digital drawing software can simulate the effects of all kinds of paper and brushes, and can also be directly introduced into the drawing software to further draw a more detailed effect. In addition, with the development of digital information, digital sketches are more convenient for displaying and communicating design projects through network media.

Two dimensional digital effect diagram. The two-dimensional digital effect diagram is completed with the help of digital technology. The principle and requirements of its drawing are basically similar to that of the traditional rendering technique. It is also a graphic technique using the color, light and shadow, the texture and the lining of the environment to display the three-dimensional effect of one angle or one side of the object, only the application is not the transmission. Unified brushes, Mark pens and other tools, but the application of graphic design software directly in the computer creation, relatively speaking faster, more effective performance.

Digital graphic art can also finish drawing of flower paper and product design drawings. With the graphic software, the design of the more fine ceramic product paper can be completed. Using the graphic function of the plane digital software, the color separation of the past tedious paper screen printing becomes easy. The drawing software using vector technology also brings higher accuracy and higher efficiency to the design of product design drawings.

\section{3 "Real" impersonator -- 3D digital art}

3D digital art creates three-dimensional model and 3D effect map through Alias, Rhino, 3ds Max and other three-dimensional software, which makes it easier and faster to realize the three-dimensional effect that can be presented by the physical model. In the design of ceramic products, 3D digital art can complete three-dimensional rendering and digital models.

Before the appearance of the three-dimensional software, our effect map should show the three-dimensional sense of the ceramic products. It is necessary to draw on the two-dimensional painting paper with the help of the light and shade relations and the perspective principle, and present a visual stereoscopic sense. This stereoscopic sense is actually a visual illusion of the human eye, and a picture can only show a visual angle of the product. If you want to show another angle, you need to redraw one. The appearance of $3 \mathrm{D}$ digital art has a revolutionary significance in the field of product design. The three-dimensional software enables us to draw accurate and real three-dimensional images in the three-dimensional space of computer simulation based on the 
designed long, wide and high data. In this process, we can rotate objects or visual angles and objects at any time. All sides of the body are observed and modified as if we are making the physical model by hand, which makes the display of the ceramic product effect more intuitive and accurate. The three-dimensional digital art can simulate the real material and light effect. Adding material to the completed ceramic product digital model and setting up the light rendering, we can get a "photo" of a ceramic product. The final form of the product which needs to be developed by the physical model and the product sample can be used three. The display of digital art can effectively shorten the design cycle and reduce costs.

\subsection{Dynamic display - Digital Animation Art}

Digital animation art, especially three-dimensional animation based on three-dimensional animation technology has been widely applied in landscape design and environmental design. The digital animation art with audio-visual language has a greater amount of information and better display and communication, which can make up for the lack of static effect map and physical model display. For example, our design of ceramic sanitary ware products, environmental ceramic decorative products, their display needs specific space, generally using the form of sample room display, but the sample room display needs large space, disassembly is not convenient, can not show different effects in a short time, high cost. Using 3D animation technology, we can simulate the display or use of ceramic products in various different spaces, and use the way of roaming animation to guide the audience to walk in the simulated space and show the application of ceramic products. Digital animation can store CD-ROM and hard disk, it is convenient to carry, can be used indefinitely, and can also be used for remote display by multimedia network technology. It can achieve the greatest publicity effect in the case of cost less.

\subsection{Precise sculptor - Digital engraving}

Digital carving technology based on numerical control technology can bring great convenience to the manufacture of ceramic products in physical models. Most of the traditional ceramic product models need to be made by hand. The molding curves and surfaces of the ceramic products are rich. It is difficult to make the curves and surfaces smooth and smooth by hand making, so it is easy to produce defects. The computer software can generate three-dimensional model directly according to the design drawings of the digital, and then import the 3D model data into the digital engraving equipment, which can engraving the model or mold of the entity, that is, it is accurate and fast.

\subsection{Real immersion - Virtual Reality Art}

Virtual reality is the use of computer technology to simulate and demonstrate the reality of the movement. By displaying three-dimensional visual images and three-dimensional sound positioning, it gives the viewer a false impression, making him feel that everything he sees and hear is true. It also allows users to move and rotate virtual products in virtual space to simulate the true use of products. With this technology, we can not only demonstrate the shape of our products, but also immerse ourselves in the virtual world to simulate the various uses of products. In the future, the virtual reality art can even feel the real sense of touch and smell, and achieve the real "immersive" situation.

\section{The advantages brought by digital art to ceramic product design}

\subsection{High accuracy and effective improvement of design quality}

In the traditional ceramic design process, the product effect drawing, the drawing of the design drawing and the production model of the product all need the designer to finish by foot. Because of the different tools quality, artificial proficiency, working environment and so on, the differences in 
the precision of the drawings and models are caused, and then the design quality is influenced.

In the process of ceramic product design based on digital art, digitized tools are easy to operate, highly accurate and easy to learn and master. The software provides an analysis program for curves and surfaces to help designers avoid mistakes in drawing. The 3D digital rendering is more real and accurate. The decorative paper can be more delicate and the surface of ceramic products can be processed more smoothly. The three-dimensional product model and production mold can be processed directly through the NC machining equipment, avoiding the error in the artificial process, ensuring the precision of the production and improving the quality of the product design.

\subsection{Shorten the development time quickly and reduce the cost}

Based on digital art, the design of ceramic products, using mouse and hand-painted equipment to replace the traditional design of paper, pen, pigment and other tools, color matching and selection, painting tools alternately need to light a mouse to complete, convenient and quick. Using the commands of storage, history, reply, and modification of the drawing software, we can easily adjust the specific steps, specific colors, specific layers, or elements. The previous modification of the time consuming effort map and drawings becomes easy and simple. In addition, using three-dimensional software, the designer can see the three-dimensional shape of the product ahead of time, and can observe and modify any angle of the 3D model. Designers and customers can see the completion of the product by watching the three-dimensional model and the real three-dimensional image of the photo. It greatly shortens the time spent on making plaster models and product samples. The 3D model based on digitization can also be directly modeled by NC machining equipment, making the production and design more closely integrated. All these shorten the cycle of ceramic product design and reduce the cost of product development.

\subsection{Easy to communicate and display}

The ceramic product design based on digital art is well adapted to the development direction of the digital information age, and the digital product design is more favorable for display, communication and communication. We can easily use the network, digital display and many other ways to display, and by e-mail, we can send our electronic effect drawings to thousands of customers in the hands of thousands of miles away. Between designers and designers, designers and customers can achieve remote collaboration through the Internet. Animation display, virtual reality display and other means can fully mobilize the viewer's senses and immerse them in the virtual environment to feel the products.

\section{Conclusion}

The design of ceramic products is the integration of technology and art. Before long, "ceramic" itself is the representative of high technology. With the development of the times, our society has entered the era of digital information, and digital art with a significant feature of computer digital media has entered our design and life. The problems facing the traditional ceramic product design are becoming more and more outstanding. How to integrate the ceramic product design and digital art organically and effectively solve the difficulties in the design of ceramic products with the help of the new digital art is a subject worth studying.

\section{References}

[1] The impact of new design on the concept of traditional ceramic design. Tang Chung Hi, China ceramic industry, 200202 issue.

[2] "Computer-aided ceramic design" Wang Jihai, "Shandong ceramics" 200103 issue.

[3] "On the characteristics of computer ceramics design performance" Yu Yong Hong Mei "China ceramic industry" 03 issue in 2007. 
[4] "Ceramic plastic arts" Yang Yongshan Higher Education Press.

[5] "Modeling design for domestic ceramics" Li Yucang, China Light Industry Press.

[6] "Modern ceramic product design" Liu Hongwei Liaoning Art Publishing House.

[7] "Computer aided design course" Zhang Bingsen Wang Yu Tsinghua University press.

[8] Introduction to digital media art, Li Si Da, Tsinghua University press.

[9] "New media art" Zhang Yanxiang Science Press. 